Anales de Geografía de la Universidad Complutense ISSN: 0211-9803

http://dx.doi.org/10.5209/AGUC.57730

\title{
La industria de refino del petróleo en Cartagena (España), 1950-2015
}

\author{
Cayetano Espejo Marín ; José María Serrano Martínez²; Alejandro Parra Castaño \\ Recibido: 19 de febrero del 2017 / Enviado a evaluar: 28 de febrero del 2017 / Aceptado: 24 de mayo del 2017
}

Resumen. En este artículo se analiza la evolución de la producción de la refinería de petróleo de Cartagena, la primera que se instala en la España Peninsular. Inaugurada en 1950, desde entonces ha sido un referente en la producción nacional de destilados del petróleo. Se detallan las decisiones políticas que llevaron a su implantación y desarrollo durante décadas. También se analizan las razones y consecuencias de su reciente modernización y ampliación. Se ha realizado una inversión superior a 3.000 millones de euros motivada por: su localización estratégica junto a uno de los mejores puertos del Mediterráneo para el trasiego de petróleo y sus derivados; su conexión con la refinería interior de Puertollano a través de un doble oleoducto; la disponibilidad de abundante suelo para las nuevas instalaciones, próximo y de titularidad propia; y la necesidad de obtener gasóleos y querosenos, productos de los que España era deficitaria.

Palabras clave: Refinería de petróleo; Cartagena; Repsol.

\section{[en] The oil retining industry in Cartagena (Spain), 1950-2015}

Abstract. This article analyzes the evolution of production at Cartagena oil refinery, the first to be installed in the Iberian Peninsula. This refinery was inaugurated in 1950, and since then has been a reference in the national production of petroleum distillates. This paper details the political decisions that led to its implementation and development for decades. We also analyze the reasons and consequences of its recent modernization and enlargement. An investment of more than 3,000 million euros has been made due to: its strategic location next to one of the best ports of the Mediterranean for the transfer of oil and its derivatives; its connection with the interior refinery of Puertollano through a double pipeline; the availability of abundant soil, near and of own ownership, for the new facilities; and the need to obtain gas oils and kerosene, products of which Spain was deficient.

Key words: Oil refinery; Cartagena (Southeastern Spain); Repsol.

1 Universidad de Murcia

E-mail: cespejo@um.es

2 Universidad de Murcia

E-mail: jmserran@um.es 


\section{[fr] L'industrie du raffinage du pétrole à Cartagena (Espagne) de 1950 à 2015}

Résumé. Cet article analyse l'évolution de la production de la raffinerie de pétrole à Cartagena, la première à être installée en Espagne. Inaugurée en 1950, elle a été depuis alors un exemple de référence dans la production nationale de distillats de pétrole. Ensuite, on examine les décisions politiques qui ont conduit à sa mise en œuvre et à son développement pendant des décennies. On analyse également les raisons et les conséquences de sa récente modernisation et son expansion. L'investissement effectué, supérieur à 3000 millions d'euros, estdu à son emplacement stratégique à côté de l'un des meilleurs ports de la Méditerranée pour le transfert de pétrole et de ses dérivés; par sa connexion avec la raffinerie intérieure de Puertollano à travers d'un oléoduc double; par la disponibilité des terrains, très proches et de fonds propre, pour construire les nouvelles installations; et le besoin d'obtenir du gazole et du kérosène, des produits déficitaire en Espagne.

Mots clefs: raffinerie de pétrole, Cartagena, Repsol.

Cómo citar. Espejo Marín, C.. Serrano Martínez, J.M y Parra Castaño, A. (2017): La industria de refino del petróleo en Cartagena (España), 1950-2015. Anales de Geografía de la Universidad Complutense, 37(2), 371-398.

Sumario. 1. Introducción y contexto. 2. La refinería de Cartagena. Inicio y desarrollo. 3. La ampliación y modernización: una nueva etapa estratégica. 4. Incidencia de la refinería sobre la actividad del Puerto de Cartagena. 5. Capacidad de refino en España. 6. Incidencia de la ampliación de la refinería de Cartagena en el sector del petróleo en España. 7. El papel de la refinería en la instalación de otras industrias energéticas del Valle de Escombreras. 7.1. La Central Térmica. 7.2. Las plantas de biocarburantes. 8. Conclusiones. 9. Referencias bibliográficas.

\section{Introducción y contexto}

El análisis geográfico del sector petrolero en España cuenta con publicaciones de gran interés porque aportan el conocimiento necesario que permite abordar la evolución de este estratégico sector. R. Puyol en el artículo "Las fuentes de energía en España: petróleo, energía nuclear y energía de sustitución" dedica un apartado a la refinación $\mathrm{y}$ analiza los cinco grupos de factores que han influido decisivamente en la implantación de las refinerías españolas: de carácter fiscal, estratégico, políticos o de política coyuntural, comerciales y económicos. También analiza con detalle la distribución de los productos petrolíferos, y elabora un cuadro con datos de 1977 en el que expone para cada refinería, la empresa propietaria, su localización, la fecha de entrada en funcionamiento, la propiedad de su capital social, su capacidad autorizada en 1979 y su capacidad prevista en 1980 (Puyol, 1978). M. Molina en sus aportaciones sobre la energía en España ha estudiado el sector del petróleo. Ocupa el capítulo 6 de su libro "Fuentes de energía y materias primas", en la Geografía de España de la editorial Síntesis, con un apartado final dedicado a la capacidad de refino. También se refiere a la localización de las refinerías, que es preferentemente costera o insular, y viene motivada por la llegada del crudo por vía marítima. Un cuadro con datos de 1986 recopila la información básica de las 10 refinerías: su empresa propietaria, localización, capacidad efectiva de producción y aportación de ésta al total nacional (Molina y Chicharro, 1990). En la misma línea se sitúan sus 
capítulos de libros "Fuentes de energía y recursos minerales", en la Geografía de España que publica la editorial Planeta (Molina, 1991); y "Las fuentes de energía", en la Geografía de España que edita Ariel en 2001. Para esta autora, la producción petrolífera se basa en la presencia de refinerías ubicadas en la costa o en interior, como sucede con Puertollano, y junto a ellas numerosos centros de almacenamiento dispersos por la costa y el interior, y una red de oleoductos (Molina, 2001).

Sobre la logística de los productos petrolíferos C. Espejo ha publicado el artículo "La distribución al por mayor de productos petrolíferos en España (Espejo, 2008); y junto a otros autores el artículo "Contribución al estudio de los biocarburantes en España", productos estos últimos que se consumen preferentemente mezclados con gasolinas y gasóleos y por tanto tienen una relación directa con las industrias del petróleo, de ahí que la mayoría de las plantas de biocarburantes construidas en nuestro país se localicen en las proximidades de las refinerías. Otros aspectos analizados son las políticas que han llevado a la implantación y fomento de los biocarburantes, los problemas que más le han afectado (competencia exterior y sobredimensionamiento de la capacidad productiva), y la evolución anual del consumo de gasóleos, gasolinas y biocarburantes entre los años 2008 y 2014, que permite ver las consecuencias de la crisis económica (Espejo, Millán y García, 2016).

Las investigaciones realizadas en España sobre energía han puesto de manifiesto que las relaciones espacio-energía son múltiples, que la discordancia entre las zonas de producción y de consumo implica su transporte y que hay una gran influencia de la energía sobre los tipos de organización espacial de los territorios (Mérenne, 2011). El análisis territorial de la energía se realiza teniendo en cuenta, al menos, tres grandes temas sobre los que los geógrafos han tendido a organizar su pensamiento: el paisaje, la relación hombre-entorno, y la distribución espacial, descripción y explicación de los fenómenos de la superficie terrestre (Haggett, 1999; Harvey, 1983). Los factores de localización de las centrales energéticas, igual que los de otras instalaciones industriales, se han identificado tradicionalmente con los históricos, naturales, técnicos y humanos (Bailly y Beguin, 1992).

Con este artículo se pretende analizar la evolución de una refinería española, que tiene como singularidad ser la primera que se instaló en la Península, en el Valle de Escombreras en Cartagena, y que gracias a su producción de fuelóleo se construyó en su proximidad la primera gran central térmica de producción eléctrica con fuelóleo de la España Peninsular. Con el paso del tiempo la refinería quedó anticuada, pero a finales de la primera década de este siglo Repsol, la compañía propietaria, optó por su ampliación y modernización con una inversión multimillonaria. Entre los factores que explican este hecho están: su localización estratégica junto a un gran puerto que amplió su dársena de Escombreras para facilitarle las operaciones necesarias de descarga de crudo y de carga de productos petrolíferos; su conexión con la refinería de Puertollano a través de un doble oleoducto propiedad de Repsol con el que se abastece de petróleo y da salida a sus producciones; la disponibilidad del suelo necesario para su expansión sobre los terrenos anexos del antiguo Poblado de Escombreras, que durante décadas fue residencia de una parte de los empleados de la 
refinería; y una razón no menos importante, la necesidad de obtener gasóleos y querosenos, productos de los que España era deficitaria.

A continuación se expone una breve evolución histórica de la refinería con los principales hechos que han afectado a su instalación y evolución de su producción; los motivos y consecuencias de su reciente ampliación y modernización y como ha afectado a la producción nacional de productos petrolíferos; la incidencia de la refinería en la actividad del Puerto de Cartagena; y por último, aludimos brevemente a dos industrias que han estado vinculadas directamente con ella: la central térmica de Hidroeléctrica Española desde 1957, y la planta de bioetanol de Ecocarburantes Españoles desde 2000, ambas pioneras en sus sectores productivos.

\section{La refinería de Cartagena. Inicio y desarrollo}

La elección del valle de Escombreras para la localización de la primera refinería peninsular se debió, en un contexto de postguerra civil, de autarquía económica y en plena Segunda Guerra Mundial, a razones fundamentalmente geopolíticas, al instalarse en un lugar bien protegido por la Base Naval de Cartagena y ser un puerto natural del Mediterráneo. Barcelona, por su proximidad a la frontera francesa, era considerada como vulnerable a un posible asalto por fuerzas extranjeras (Centeno, 1976). En última instancia, la implantación de la refinería de Cartagena fue determinación de Franco en virtud de consideraciones militares y estratégicas más que económicas (Puyol, 1978; Tortella, Ballestero y Díaz, 2003).

El 22 de enero de 1942 se publica un Decreto por el que se encomienda al Instituto Nacional de Industria (INI) la misión y responsabilidad de organizar empresas que tengan como finalidad la obtención de hidrocarburos de cualquier clase a partir de la destilación de pizarras bituminosas en España. El INI centraliza desde esta fecha todas las participaciones del Estado en empresas dedicadas a dichas actividades, canalizando además la posible iniciativa privada. La consecuencia inmediata de este Decreto es la creación por parte del INI de la Empresa Nacional Calvo Sotelo de Combustibles Líquidos y Lubricantes (Encaso), que queda constituida como Sociedad Anónima el 24 de noviembre de 1942, y que comienza sus actividades en la zona de Puertollano y Levante, encargándose de la construcción de la refinería de Cartagena (Comisión Nacional de Energía, 2006).

El proyecto de Cartagena era de las iniciativas consideradas vitales por el INI dentro de la política autárquica del momento (Ballestero, 1993). En la refinería de Cartagena se proyectaba la obtención de carburantes y lubricantes a partir de crudos importados y pizarras, pero también a partir de hidrocarburos obtenidos por destilación de carbones y pizarras. Se contemplan unas instalaciones capaces de tratar 400.000 toneladas anuales (Tm/año) de petróleo para la obtención de gasolinas, queroseno, gasóleo y fuelóleo, así como $50.000 \mathrm{Tm} / \mathrm{año}$ de aceites parafinados, cifras que permitirían cubrir una parte importante de la demanda nacional (Martín y Comín, 1991). 
La Ley de 26 de Mayo de 1944 aprueba el Plan para la Fabricación Nacional de Combustibles y Lubricantes e Industrias Conexas, y de cuyo desarrollo y ejecución se encarga al INI. Este Plan contempla la construcción de varias fábricas para la obtención de combustibles líquidos y lubricantes por tratamiento de pizarras y lignitos en Puertollano, Tarragona y La Coruña. Además, el Plan aprueba el tratamiento de crudos en la refinería de Cartagena (Comisión Nacional de Energía, 2006).

Si se tiene en cuenta que en 1946 Murcia acaparó el 9\% del capital desembolsado por el INI, Aragón el 8,4\%, y Castilla-La Mancha el 8\%, hay que reconocer que las inversiones iniciales del INI afluyen hacia las zonas menos industrializadas de España. En Murcia el INI se implantó en el sector energético y minero con el $10 \%$ del sector, y en la industria de cabecera Encaso con el $22 \%$ de la inversión del INI en ese sector (Martín y Comín, 1990).

Hacia 1947 se había terminado la construcción de parte de las instalaciones fijas, pero faltaban las unidades de destilación y las de refino térmico y polimerización catalítica. A la vista del retraso y de los continuos problemas de suministro y de financiación, se planteó la creación de una nueva empresa, desgajada de Encaso, con participación de capitales privados nacionales (Cepsa) y extranjeros, a la que Encaso aportaría la refinería, y los nuevos socios la financiación para la compra de los equipos necesarios para completar el proyecto, además de asistencia técnica. En la primavera de 1948 los responsables del INI inician las negociaciones con la Compañía Española de Petróleos (Cepsa), con la sociedad americana California Texas Oil Products Co. (Caltex) y con Socony Vacum Oil (Socony), que se comprometía a aportar las divisas necesarias para terminar las instalaciones de Cartagena. Con Socony las negociaciones fracasaron pronto, pero se mantuvieron con Cepsa y con Caltex, que también aseguraba traer las divisas para la terminación de las obras. Los acuerdos se cerraron el 30 de julio de 1948 en un convenio de bases suscrito en Nueva York por las tres entidades, que preveía la constitución de una empresa para la terminación y explotación de la refinería de Cartagena. Caltex aportaría a la nueva sociedad, que se denominaría "Refinería de Petróleos de Escombreras" (Repesa), un $24 \%$ del capital en dólares y un préstamo de 8 millones de dólares para financiar la construcción; igualmente, Caltex se reservaba el suministro de la totalidad de las necesidades de crudo mientras estuviera vivo el préstamo, y de al menos un $50 \%$ de estas necesidades por un plazo de quince años. Por su parte, el INI aportaba las instalaciones de Cartagena, que pasaban a ser de su propiedad tras la correspondiente compra a Encaso (Martín y Comín, 1991).

A finales de 1948 se concretaron nuevos aspectos del convenio. El capital social se fijó en 325 millones de pesetas, ampliables en lo necesario para, en un futuro próximo, incrementar la capacidad de la refinería hasta los 20.000 barriles diarios; Encaso suscribiría el $52 \%$ y Cepsa y Caltex se repartían en partes iguales el $48 \%$ restante. Encaso cedía a la nueva sociedad, en concepto parcial de su aportación, su factoría de Escombreras, valorada en 138.823 .466 pesetas. También se aprobó el contrato de suministro de crudos a la futura entidad por parte de Caltex y, asimismo, se acordó la fijación de los cambios especiales que debían aplicarse a las aportaciones que, en 
dólares, realizaría esta última. En el momento de la firma surgió un último e importante escollo. Caltex se alarmó ante los peligros que se derivaban de las facultades expropiatorias que otorgaba al INI su Ley fundacional, y requirió de las autoridades del INI que renunciasen expresamente a ellas. Se aceptó dicha condición señalándose de forma expresa que no serían de aplicación los artículos expropiatorios contenidos en la Ley y en el Reglamento; el INI, por tanto, renunciaba de un modo explícito, pleno y sin salvedad alguna a hacer uso de dicha facultad (Martín y Comín, 1991).

El 27 de junio de 1949 se firma la escritura de constitución de la nueva empresa mixta Refinería de Petróleos de Escombreras, S.A. (Repesa), con el capital antes indicado, y con el fin social de proceder a la "importación de crudos en general, la construcción y explotación de refinerías, la obtención de derivados del petróleo, el aprovechamiento del subproductos y el comercio relacionado con todos estos productos". Como presidente fue nombrado José María de Lapuerta y de las Pozas, que era consejero del INI en representación del Ministerio de Hacienda y como vicepresidente se designó a Demetrio Carceller, que había sido Ministro de Industria y Comercio (Martín y Comín, 1991).

Tras la constitución de la compañía, los trabajos de organización e instalación se aceleraron; en 1949 se completó el montaje de la unidad de destilación a presión atmosférica y vacío, por la empresa americana Foster Wheeler Co. Al mismo tiempo se prepararon las instalaciones del puerto de Escombreras para la recepción de petróleo y en octubre se recibieron los primeros cargamentos de crudo. En el segundo semestre de 1949 se proyectó la ampliación de la capacidad de producción básica hasta los 20.000 barriles diarios. La sociedad comenzó las operaciones de refino en enero de 1950, con una capacidad de 5.000 barriles diarios. El Decreto de 9 de febrero de 1951 eleva la capacidad de la refinería a 30.000 barriles de petróleo por día, lo que llevó consigo un aumento de la participación de los productos de Repesa en el abastecimiento nacional de carburantes y combustibles líquidos.

Figura 1. Refinería de Cartagena en los años cincuenta.

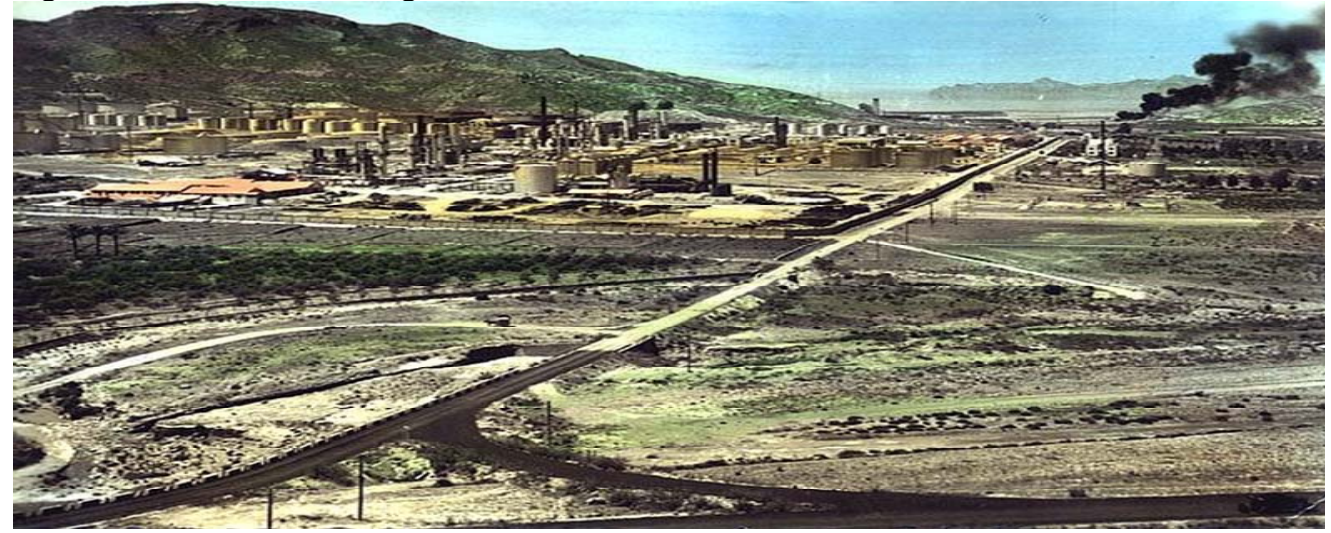

Fuente: Cortesía de D. Zacarías Conesa Estévez. 
A partir de 1954 la evolución del consumo de productos petrolíferos y el hecho de ser la única refinería de la Península exigió un nuevo incremento en la capacidad de destilación, hasta los 3,5 millones de Tm/año (Decreto de 24 de diciembre de 1954), y en 1958 se aprobó una nueva ampliación (por Decreto de 28 de marzo) hasta los 5,5 millones de Tm. Para poder ampliar hasta 3,5 millones de Tm/año se llegó a un acuerdo con Caltex para la financiación de las inversiones, y sobre todo para contar con la garantía del suministro de crudo. Ante esta nueva situación, el INI mantiene en paralelo otra negociación con Shell, que también estaba interesada por suministrar petróleo al creciente mercado español. Como consecuencia de ello el 4 de diciembre de 1954 se firman dos contratos, uno con Caltex y otro con Shell, que en conjunto suponían un importante volumen de financiación, a favor el INI (5 millones de libras esterlinas) y a favor de Repesa (7,5 millones de dólares), que se reembolsarían con una prima en las compras de crudo. Además Caltex adquiría el derecho a suministrar el $75 \%$ de las necesidades de Cartagena y Shell el $25 \%$ restante. Repesa no sólo se convirtió en el proyecto más exitoso y rentable del INI, sino que permitió a este organismo generar divisas en un momento de extraordinaria penuria en esta materia (Tortella, Ballestero y Díaz, 2003).

Asimismo la empresa inició la constitución de una flota de transporte propia, con la adquisición de dos buques-tanque en 1958 y otros dos en 1959. Por otra parte, en 1959 se constituyó la empresa Butano para la distribución del gas producido por la refinería, con la partición de Repesa con un 50\% y de Campsa con el resto (Martín y Comín, 1991).

Campsa es la Compañía Arrendataria del Monopolio de Petróleos, creado en el Real Decreto-Ley de 28 de junio de 1927, durante la Dictadura del General Primo de Rivera, y cuyas funciones principales son: la importación de crudos y productos petrolíferos, el refino de productos petrolíferos, el almacenamiento de crudo y productos petrolíferos, la distribución de productos petrolíferos, la venta al por menor de productos petrolíferos, y la explotación y producción de hidrocarburos en España. Campsa es una sociedad anónima cuyos socios son los principales bancos españoles, y según lo estipulado en el citado Decreto-Ley se reserva al Estado una participación del 30\% en la sociedad (Comisión Nacional de Energía, 2006).

Con el Decreto de Refinerías del 9 de marzo de 1968 Repesa consolida en 6 millones de Tm/año la cifra de suministros al Monopolio de Campsa, aunque su capacidad real de destilación era de unos 10 millones de Tm/año. En este nuevo escenario se pone de manifiesto un cierto conflicto de intereses entre Cepsa y Repesa, ya que la primera, con el Decreto, consigue que su nueva refinería de Algeciras, inaugurada en 1967, participe en el suministro al mercado nacional y, por tanto, de alguna manera compita por el hinterland de Cartagena. Por ello en abril de 1968 Cepsa vende su paquete accionarial de Repesa (24\%), siendo los compradores Caltex $(16 \%)$, con lo que su participación aumentaba hasta el máximo permitido por el Decreto que era del $40 \%$, Demetrio Carceller (4\%) y el propio personal de Repesa (4\%) (Tortella, Ballestero y Díaz, 2003). 
Figura 2. Planta de envasado de lubricantes Repsol, marca que da nombre a la actual multinacional.

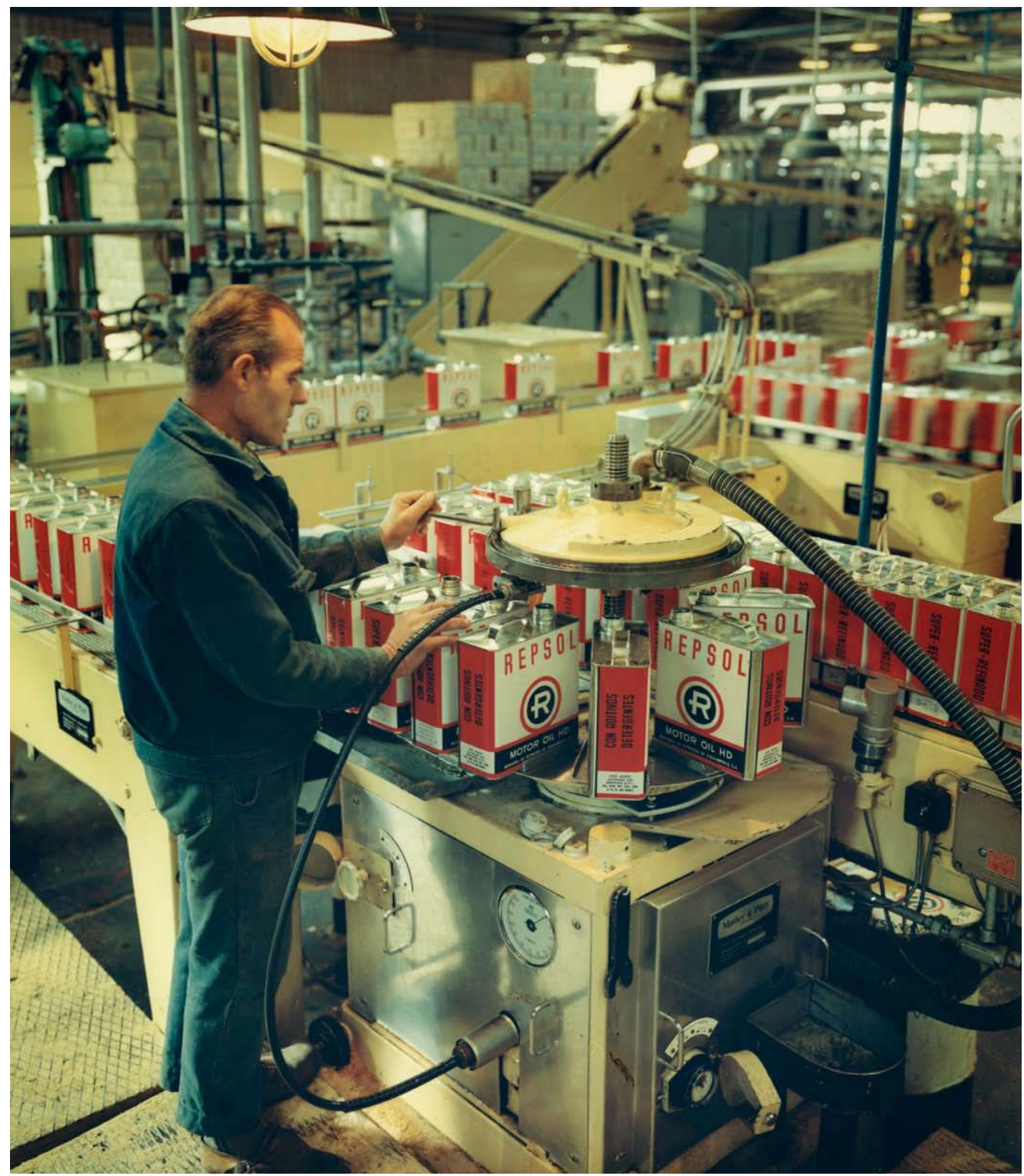

Fuente: Repsol.

El 1 de octubre de 1969 se produce en la refinería de Cartagena un trágico incendio (Figura 3) que se saldó con el fallecimiento de cinco empleados y que se extinguió nueve días después, gracias a la ayuda de la Armada. 
Figura 3. Incendio de la refinería de Cartagena (1969).

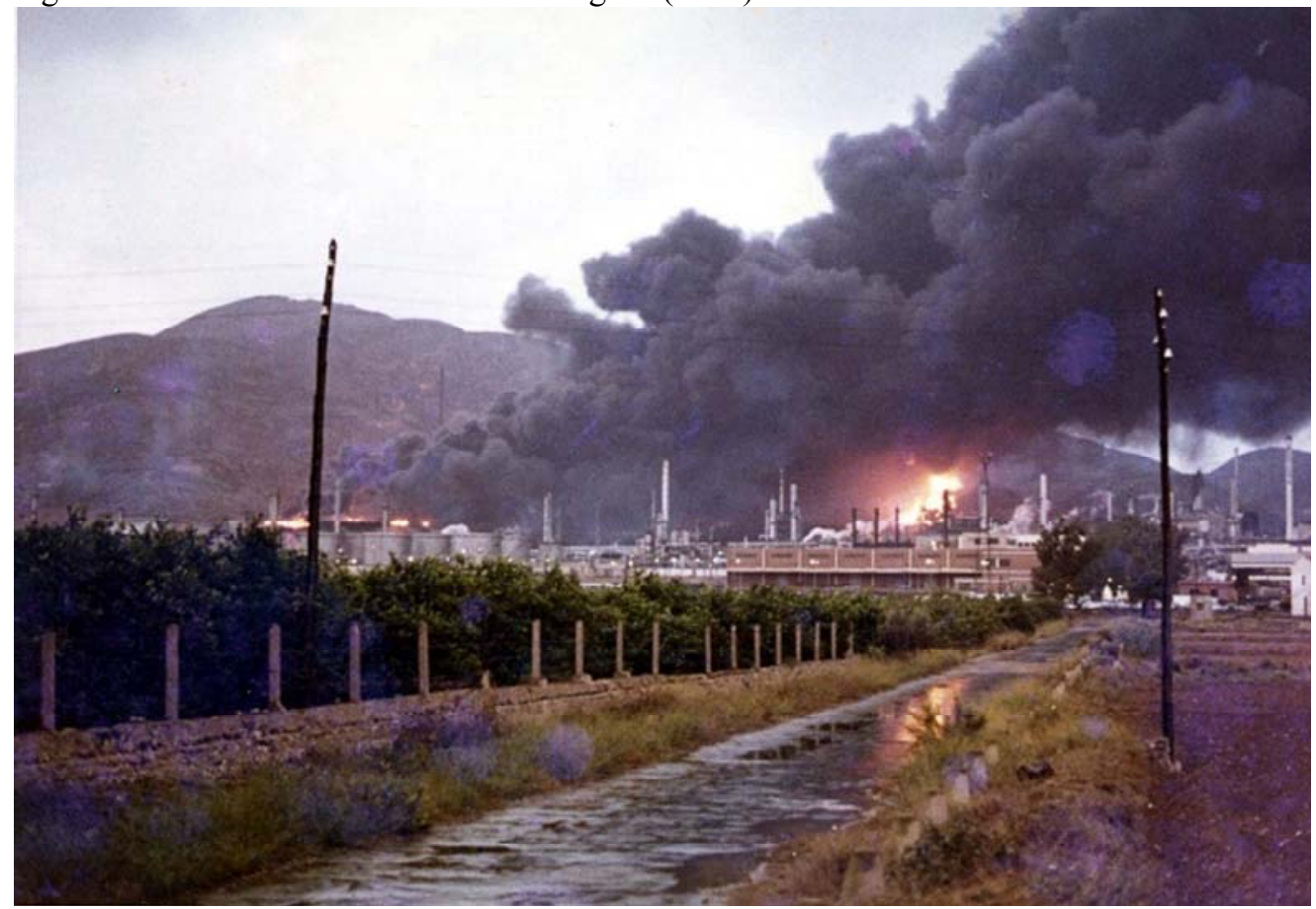

Fuente: Cortesía de D. Zacarías Conesa Estévez.

Entre 1965 y 1975 el INI consolidó su presencia en los hidrocarburos, de tal modo que se impuso una reestructuración de sus diferentes empresas participadas. Por ello mediante el Decreto 2611/1974 de 9 de agosto se aprueba la fusión de Encaso, Entasa (Empresa Nacional de Petróleos de Tarragona, S.A.) y Repesa mediante absorción por esta última de las dos primeras. La empresa resultante pasa a denominarse Empresa Nacional del Petróleo (Enpetrol). Poco antes de confirmarse la fusión, Repesa había finalmente conseguido el reconocimiento oficial de su capacidad de 10 millones de Tm/año de destilación, fijadas por Decreto del Ministerio de Industria, donde se reflejaban las capacidades de todas las refinerías nacionales para el año 1980. De esta manera se cerraba un ciclo de aproximadamente 25 años, en el que la refinería del Valle de Escombreras constituyó el germen de la industria de refino de España (Tortella, Ballestero y Díaz, 2003). Hacia 1976 esta nueva empresa era, según su inmovilizado neto, ventas y empleo, una de las mayores y más rentables empresas del INI, que era propietario del 71,8 \% del capital social, frente al $22 \%$ del Chevron Oceanic y Texaco y pequeños accionistas privados españoles (Martín y Comín, 1991).

Con la aprobación del Decreto 418/1968 de 9 de Marzo, sobre el Régimen de Autorización de las Refinerías de Petróleos, se establecen unas nuevas normas de funcionamiento para el sector petrolero español. A partir de ahora es el Gobierno quien estima la necesidad de una nueva refinería y su emplazamiento, así como la 
capacidad de la instalación y el conjunto de productos a obtener. Hasta la fecha eran las empresas las que solicitaban autorización para la construcción de las instalaciones en un punto determinado. Consecuencia de la nueva normativa fue la creación de las refinerías de Bilbao y Tarragona, autorizadas en 1968 y 1971. Desde entonces no se ha vuelto a construir una nueva refinería en España, por lo que el parque de refinerías asciende a diez, con una capacidad potencial de destilación de 72,1 millones de Tm a mediados de los años ochenta; y de 65, 6 millones de Tm a finales de 2006, año en que la materia prima procesada asciende a 61,9 millones de Tm (Espejo, 2008a).

La etapa 1975-1985 va a resultar decisiva para el enclave energético del Valle de Escombreras, y en particular para Repesa. Además del cambio de denominación, la refinería de Enpetrol-Cartagena se vería especialmente afectada por las dos crisis petroleras mundiales de 1973 y 1979, así como por decisiones previas de política energética en el contexto nacional, en los ámbitos del petróleo y la energía nuclear, que le repercutirían de forma significativa.

A lo largo de los años setenta y especialmente desde 1975, la capacidad de tratamiento de petróleo experimentó en todo el parque un fuerte crecimiento, provocado por la puesta en funcionamiento de las dos últimas refinerías autorizadas en Vizcaya y Tarragona, y por las ampliaciones de capacidad en todas las existentes, salvo precisamente la de Escombreras. En contra de lo que sucedía en el contexto europeo, la capacidad instalada global creció un 43\%, al pasar de 50,4 millones de Tm/año en 1973 a 72,1 millones en 1980. Este sustancial crecimiento de la capacidad de tratamiento coincide con la escalada de precios del petróleo; cuando éstos fueron debidamente repercutidos en el mercado se frenó la demanda, y se produjo una rápida caída en el índice de utilización de la capacidad productiva de las refinerías españolas, que pasó del 92,2 \% de 1974 al 63,1 \% del 1982, año en que el indicador tocó suelo (Cortina, 1998).

Al sobredimensionamiento durante los años setenta de la capacidad de destilación de petróleo en España, se une el nacimiento y la expansión del programa nuclear, que implica una reducción de la producción de fuelóleo, lo que agudiza la caída de la actividad en la refinería de Enpetrol en Cartagena. Así, la capacidad de esta refinería que desde 1969 tenía autorizados 10 millones de Tm/año, pasó en 1977 a 7 millones, para alcanzar en 1985 los cinco millones de Tm/año (Cuadro 1). 
Cuadro 1. Evolución del petróleo destilado en la refinería de Cartagena. 1950-1985.

\begin{tabular}{|c|c|c|c|}
\hline Año & Miles de Tm & Año & Miles de Tm \\
\hline 1950 & 268,9 & 1968 & $6.851,2$ \\
\hline 1951 & 354,7 & 1969 & $7.024,9$ \\
\hline 1952 & 883,9 & 1970 & $8.833,0$ \\
\hline 1953 & $1.483,5$ & 1971 & $9.054,9$ \\
\hline 1954 & $1.821,9$ & 1972 & $8.945,6$ \\
\hline 1955 & $2.027,2$ & 1973 & $8.833,8$ \\
\hline 1956 & $2.158,0$ & 1974 & $8.577,7$ \\
\hline 1957 & $3.245,9$ & 1975 & $7.827,2$ \\
\hline 1958 & $3.972,8$ & 1976 & $7.279,7$ \\
\hline 1959 & $4.001,2$ & 1977 & $7.073,5$ \\
\hline 1960 & $4.024,0$ & 1978 & $6.351,6$ \\
\hline 1961 & $4.718,2$ & 1979 & $6.812,8$ \\
\hline 1962 & $5.520,2$ & 1980 & $6.560,8$ \\
\hline 1963 & $5.705,6$ & 1981 & $5.812,3$ \\
\hline 1964 & $5.839,3$ & 1982 & $5.678,0$ \\
\hline 1965 & $5.904,9$ & 1983 & $4.442,0$ \\
\hline 1966 & $5.802,8$ & 1984 & $4.334,9$ \\
\hline 1967 & $6.336,9$ & 1985 & $3.551,0$ \\
\hline
\end{tabular}

Fuente: Repsol.

En 1985, tal y como se contemplaba en la Ley 45/84, el Instituto Nacional de Hidrocarburos (INH) transfiere la mayoría de su participación en Campsa a las tres empresas públicas que en ese momento poseen activos de refino en España: Petronor (titular de la refinería de Bilbao), Petromed (titular de la refinería de Castellón) y la que luego sería Repsol Petróleo, que nace en 1987 (titular de las refinerías de La Coruña, Tarragona, Cartagena y Puertollano) (Comisión Nacional de Energía, 2006).

A mediados de los años ochenta el parque refinador español se encuentra constituido por 10 refinerías, que totalizan una capacidad de destilación atmosférica de 62,1 millones de Tm, y que son propiedad de seis compañías públicas y privadas (Cuadro 2). Enpetrol, dependiente del Instituto Nacional de Hidrocarburos, agrupa los intereses públicos y es propietaria de las refinerías de Cartagena, Puertollano, Tarragona y La Coruña. Su capacidad instalada conjunta es de 25 millones de Tm. El sector privado está representado por las compañías Cepsa (refinerías de Tenerife y Algeciras), con 14,5 millones de Tm.; Petronor (refinería de Somorrostro), con 11 millones de Tm; Petromed (refinería de Castellón), con 6 millones; y Explosivos Río Tinto (refinería de Huelva) con 4 millones de Tm. En conjunto, el sector privado cuenta con una capacidad instalada de 35,5 millones de Tm. Finalmente, la compañía mixta Asesa, propiedad al 50\% de la empresa pública Enpetrol y de la privada Cepsa, posee una refinería en Tarragona con 1,6 millones de Tm de capacidad, dedicada única y exclusivamente a la fabricación de asfaltos (Santamaría, 1988). 
Cuadro 2. Instalaciones de refino de petróleo en España.1986.

\begin{tabular}{|c|c|c|c|c|}
\hline Compañía & Refinería & $\begin{array}{l}\text { Evolución de la capaci- } \\
\text { dad autorizada Mt }\end{array}$ & $\begin{array}{l}\text { Capacidad } \\
\text { máxima } \\
\text { autorizada } \mathrm{Mt}\end{array}$ & $\begin{array}{l}\text { Capacidad } \\
\text { real } \\
\mathrm{Mt}\end{array}$ \\
\hline \multirow[t]{4}{*}{$\begin{array}{c}\text { Empresa } \\
\text { Nacional del } \\
\text { Petróleo }\end{array}$} & Escombreras & $\begin{array}{l}1,2(1949) ; 1,8(1951) ; \\
3,5 \text { (1954); 5,5 (1958); } 8 \\
\quad(1967) ; 10(1975)\end{array}$ & 10 & 5,0 \\
\hline & Puertollano & $\begin{array}{c}2 \text { (1965); } 6(1969) ; 7 \\
(1975)\end{array}$ & 7 & 6,0 \\
\hline & La Coruña & $\begin{array}{c}2 \text { (1966); } 4 \text { (1967); } 5 \\
\text { (1975); } 7 \text { (1977) }\end{array}$ & 7 & 6,0 \\
\hline & Tarragona & $\begin{array}{c}7 \text { (1974); } 8 \text { (1976), } 12 \\
(1978) ; 14(1980)\end{array}$ & 14 & 8,0 \\
\hline \multirow[t]{2}{*}{ Cepsa } & Tenerife & $\begin{array}{l}\text { Inicial n.d. (1929); } 8 \\
\text { (1967) }\end{array}$ & 8 & 6,5 \\
\hline & Algeciras & $\begin{array}{l}2 \text { (1967); } 4 \text { (1967); 6,5 } \\
\text { (1976); } 8 \text { (1977) }\end{array}$ & 8 & 8,0 \\
\hline Petromed & Castellón & $\begin{array}{c}3 \text { (1967); } 4 \text { (1967); } 8 \\
(1976) ; 6(1978)\end{array}$ & 6 & 6,0 \\
\hline $\begin{array}{l}\text { Exposivos río } \\
\text { tinto } \\
\end{array}$ & Huelva & $\begin{array}{c}2(1967) ; 4(1967) ; 8 \\
(1976)\end{array}$ & 8 & 4,0 \\
\hline Petronor & Somorrostro & $\begin{array}{c}5(1971) ; 8(1976) ; 12 \\
(1977)\end{array}$ & 12 & 11,0 \\
\hline Asesa & Tarragona & $\begin{array}{c}07 \text { (1967); 1,1 (1974); } \\
\text { 1,6 (n.d.) }\end{array}$ & 1,6 & 1,6 \\
\hline Total & & & 81,6 & 62,1 \\
\hline
\end{tabular}

Fuente: Javier Santamaría (1988): El petróleo en España del monopolio a la libertad.

A finales del siglo XX la refinería de Cartagena dispone de un terminal marítimo con 8 frentes de atraque y un parque de almacenamiento. Tiene una capacidad de refino de 5 millones de Tm/año. Posee una planta de lubricantes con una capacidad de $135.000 \mathrm{Tm} /$ año y una planta de producción de asfaltos con capacidad de 300.000 Tm/año. Dispone de una capacidad de almacenamiento de materias primas de 1.927.000 Tm y de $1.205 .000 \mathrm{~m}^{3}$ de productos (Espejo, 2008a).

\section{La ampliación y modernización: una nueva etapa estratégica}

En diciembre de 2007 el Consejo de Administración de Repsol toma la decisión de aprobar una inversión de más de 3.000 millones de euros, la más importante en la historia industrial de España, para incrementar la capacidad y la eficiencia de la refinería de Cartagena. Para M. Fernández, Director del Proyecto y miembro de la Dirección de Tecnología e Ingeniería de Repsol, la materialización de un proyecto de esta envergadura y complejidad plantea numerosos retos que van desde el ámbito de su gestión global hasta la puesta en marcha de la instalación, pasando por la 
disponibilidad de recursos en cantidad y calidad suficientes para ejecutar el proyecto con plenas garantías (Fernández, 2008).

Según Repsol, el proyecto era indispensable para el futuro del complejo industrial de la ciudad, además de parte de la estrategia global de Repsol. La refinería contaba con una baja capacidad de conversión, por lo que los porcentajes del barril de crudo obtenidos no respondían a la demanda del mercado español de carburantes. A ello se unía el hecho de que la producción era muy reducida en gasóleo, al contrario de lo que ocurría con la gasolina y el fuelóleo, productos con una demanda a la baja, y por tanto, con elevados excedentes. España es un país cuyo parque automovilístico se compone mayoritariamente de motores diésel, carburante que es deficitario, lo que obliga a importar más de 10 millones de toneladas al año. Con estas circunstancias, y dada la escasa conversión de la refinería de Cartagena, se hacía necesaria la inversión en la mejora de instalaciones y procesos productivos, de modo que respondieran a las necesidades del mercado y a las calidades medioambientales que Repsol exige a todos sus productos e impone en todas sus actuaciones (Repsol, 2012a).

Al estar emplazada en un núcleo eminentemente industrial, la refinería de Cartagena cuenta con una serie de instalaciones anexas únicas. Asimismo, muchas de las empresas ubicadas en Escombreras ofrecen sus servicios de forma recíproca, reduciendo así la logística derivada del intercambio de productos. Además de su singular ubicación geográfica, otra de las ventajas con las que cuenta el Valle es la Dársena de Escombreras, uno de los puertos más seguros del Mediterráneo desde el que, a través de un complejo sistema de tuberías, se envía producto de forma segura y eficiente a las plantas industriales localizadas en el enclave. El Terminal Marítimo de Cartagena, que también suministra crudo al Complejo Industrial de Puertollano al que está unido a través de un oleoducto, era susceptible de ampliarse. Por ello se construyeron nuevos frentes de atraque con los que dar respuesta al aumento en el número de buques que traería consigo el incremento de producción de la refinería. En la actualidad, el Terminal Marítimo del complejo industrial cuenta con ocho frentes operativos y puede recibir buques de hasta 315.000 toneladas de capacidad.

En lo referente a la superficie que había de ocupar el proyecto, Repsol contaba previamente con terrenos suficientes para albergar las nuevas instalaciones, que abarcan unas 60 hectáreas. Una superficie que, además, era colindante con las instalaciones existentes, con lo que las conexiones entre las unidades que ya existían y las nuevas resultaban más sencillas, pudiéndose utilizar todas las infraestructuras y servicios de la refinería existente (tanques de almacenamiento, instalaciones portuarias, calderas de vapor y redes de energía, estaciones de bombeo del oleoducto de crudo...) (Repsol, 2012a).

El nombre interno con el que se ha denominado al proyecto de ampliación del Complejo Industrial de Cartagena es C10, la letra por Cartagena y el número por ser el décimo gran proyecto que se diseñaba para esta refinería. El proyecto de ampliación ha consistido en la construcción de nuevas plantas de proceso y auxiliares para, principalmente, incrementar la producción de destilados medios (diésel y queroseno). La meta era aumentar el nivel de conversión del complejo industrial y 
transformarlo en uno de los centros más competitivos de Europa. Un objetivo cumplido porque dicho nivel se ha incrementado hasta un $92 \%$. Estas nuevas unidades añaden valor a los productos, ya que permiten obtener combustibles de alta calidad y con unas características medioambientales de primer nivel, mejorando en todos los aspectos las especificaciones más restrictivas en cuanto a calidad y composición. Las singulares características del Valle de Escombreras, en el que se ubica la refinería de Cartagena, fueron determinantes en la decisión de Repsol de desarrollar en ella la ampliación. Este polo industrial, eminentemente energético, está rodeado por colinas y mar, y aislado de los núcleos de población cercanos (Repsol, 2012a).

Figura 4. Evolución del petróleo destilado en la refinería de Cartagena. 1986-2015.

Miles de Tm

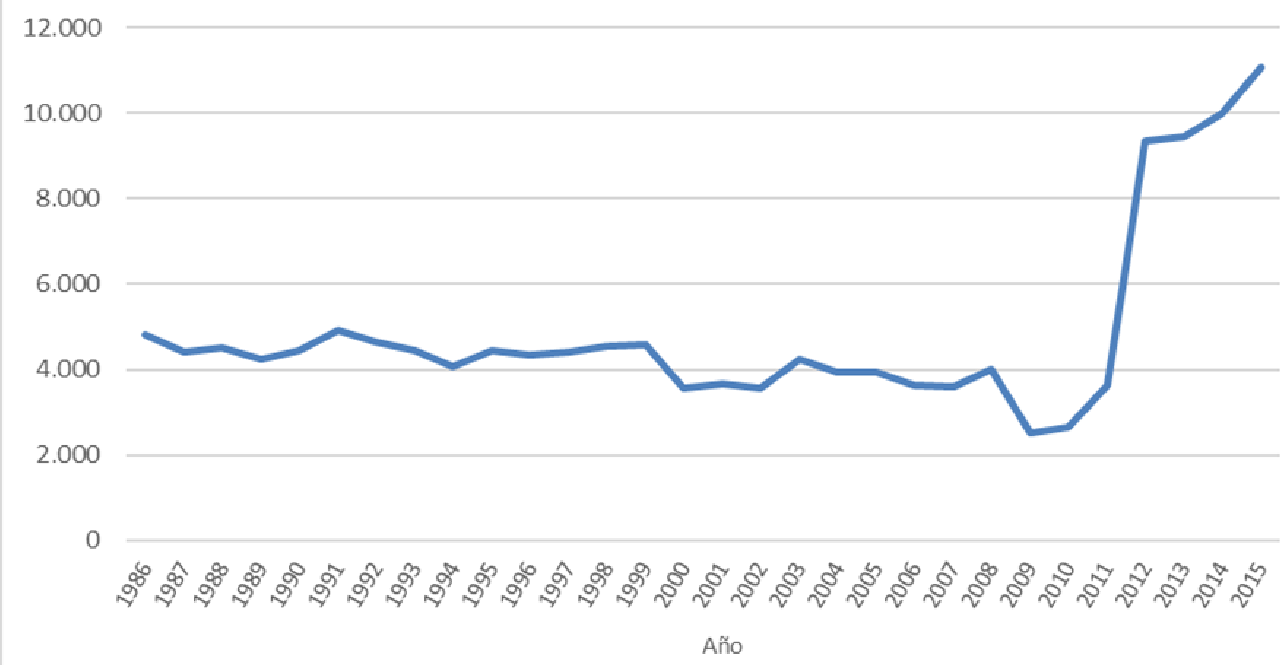

Fuente: Repsol.

Después de cuatro años de incesante labor, en la que han participado más de 20.000 personas, el resultado es una refinería moderna que se sitúa entre las más eficientes de Europa (Figura 5). Las más de 30 nuevas plantas permiten procesar crudos pesados y maximizar la producción de destilados medios, principalmente gasóleo y queroseno, de mayor demanda, aumentando la sostenibilidad de todo nuestro sistema de refino. Con ello se reduce en un $30 \%$ la importación de estos productos, lo que permite contribuir a la reducción del déficit comercial de España. El apoyo de las Administraciones públicas y de la sociedad cartagenera han sido fundamentales para impulsar el carácter dinamizador del Valle de Escombreras. La ampliación de la refinería ha impulsado la creación de empleos estables y de calidad, no solo en Repsol, sino también en otras empresas de Cartagena y del resto de la 
Región, que ofrecen diferentes servicios al complejo industrial. Las obras de ampliación han supuesto un reto logístico y organizativo sin precedentes, que se ha completado con niveles de calidad, seguridad y respeto medioambiental muy elevados (Brufau, 2012).

Repsol cuenta en Cartagena con uno de sus parques de almacenamiento más importantes. En la actualidad, en la refinería existen más de 200 tanques que albergan alrededor de 4 millones de metros cúbicos de hidrocarburos. De ellos, 1,1 millones de metros cúbicos de crudo y 400.000 de gasóleo son reservas estratégicas que el Gobierno de España utilizaría en caso de desabastecimiento nacional de combustible. Otra parte del almacenamiento está dedicada a productos terminados, desde donde se envían a la red de distribución nacional, a la que Repsol aporta desde Cartagena cerca de 8 millones de metros cúbicos al año (Repsol, 2012b).

Como se refleja en el cuadro 3, la ampliación de la refinería ha triplicado el volumen de petróleo destilado en 2015 respecto a 2011. Este incremento no se ha dado de igual modo para todos los productos (Cuadro 4). La ampliación y reforma ha conllevado la reestructuración en la producción y la intensificación de determinados destilados.

Cuadro 3. Evolución del petróleo destilado en la refinería de Cartagena. 1986-2015.

\begin{tabular}{|c|c|c|c|}
\hline Año & Miles de Tm & Año & Miles de Tm \\
\hline 1986 & 4.809 & 2001 & 3.650 \\
\hline 1987 & 4.416 & 2002 & 3.560 \\
\hline 1988 & 4.512 & 2003 & 4.233 \\
\hline 1989 & 4.249 & 2004 & 3.943 \\
\hline 1990 & 4.454 & 2005 & 3.926 \\
\hline 1991 & 4.923 & 2006 & 3.618 \\
\hline 1992 & 4.659 & 2007 & 3.611 \\
\hline 1993 & 4.448 & 2008 & 4.011 \\
\hline 1994 & 4.060 & 2009 & 2.518 \\
\hline 1995 & 4.437 & 2010 & 2.664 \\
\hline 1996 & 4.332 & 2011 & 3.640 \\
\hline 1997 & 4.392 & 2012 & 9.361 \\
\hline 1998 & 4.532 & 2013 & 9.442 \\
\hline 1999 & 4.572 & 2014 & 10.003 \\
\hline 2000 & 3.572 & 2015 & 11.067 \\
\hline
\end{tabular}

Fuente: Repsol. 
Cuadro 4. Productos petrolíferos obtenidos en la refinería de Cartagena 2000-2015. Tm.

\begin{tabular}{|l|r|r|r|r|r|r|r|r|}
\hline & Gasóleo & Fuelóleo & Naftas & $\begin{array}{c}\text { Gases } \\
\text { licuados } \\
\text { del } \\
\text { petróleo }\end{array}$ & $\begin{array}{c}\text { Gasolinas } \\
\text { de } \\
\text { automo- } \\
\text { ción }\end{array}$ & $\begin{array}{c}\text { Queroseno } \\
\text { aviación }\end{array}$ & $\begin{array}{c}\text { Gasóleo } \\
\text { pesado de } \\
\text { vacío }\end{array}$ & Total \\
\hline 2000 & 1.555 .493 & 986.946 & 278.501 & 96.743 & 810.277 & 209.881 & 153.840 & 4.091 .681 \\
\hline 2001 & 1.637 .241 & 921.822 & 316.208 & 78.108 & 734.508 & 230.262 & 155.164 & 4.073 .313 \\
\hline 2002 & 1.737 .674 & 1.168 .167 & 234.355 & 104.475 & 721.827 & 157.041 & 86.299 & 4.209 .838 \\
\hline 2003 & 2.337 .101 & 1.116 .547 & 279.611 & 124.124 & 734.130 & 139.776 & 214.703 & 4.945 .992 \\
\hline 2004 & 2.372 .752 & 1.035 .880 & 250.767 & 90.699 & 733.157 & 163.443 & 172.129 & 4.818 .827 \\
\hline 2005 & 2.281 .270 & 1.093 .902 & 262.626 & 123.791 & 728.663 & 178.181 & 243.152 & 4.911 .585 \\
\hline 2006 & 2.276 .260 & 1.026 .409 & 330.626 & 103.076 & 567.426 & 221.275 & 258.712 & 4.783 .784 \\
\hline 2007 & 2.296 .710 & 740.413 & 220.455 & 72.870 & 572.097 & 237.286 & 242.628 & 4.382 .459 \\
\hline 2008 & 2.207 .336 & 1.155 .225 & 220.377 & 86.266 & 490.794 & 204.547 & 162.174 & 4.526 .719 \\
\hline 2009 & 1.597 .242 & 392.161 & 185.745 & 56.818 & 387.724 & 118.469 & 101.005 & 2.839 .164 \\
\hline 2010 & 1.397 .894 & 457.188 & 139.946 & 44.104 & 379.540 & 200.659 & 172.650 & 2.791 .981 \\
\hline 2011 & 1.812 .106 & 475.261 & 370.444 & 68.564 & 414.491 & 279.143 & 175.246 & 3.595 .255 \\
\hline 2012 & 4.726 .102 & 186.439 & 1.666 .893 & 194.128 & 193.599 & 752.736 & 133.423 & 7.853 .320 \\
\hline 2013 & 5.211 .748 & 129.233 & 1.988 .762 & 194.077 & 206.361 & 871.489 & 207.180 & 8.808 .850 \\
\hline 2014 & 5.407 .043 & 123.097 & 2.059 .487 & 182.074 & 244.934 & 997.701 & 573.172 & 9.587 .508 \\
\hline 2015 & 5.844 .824 & 84.056 & 2.018 .628 & 222.454 & 501.768 & 1.149 .543 & 410.667 & 10.231 .940 \\
\hline
\end{tabular}

Fuente: Repsol.

Figura 5. La refinería de Cartagena convertida en una de las de mayor capacidad e innovación en España. 2012

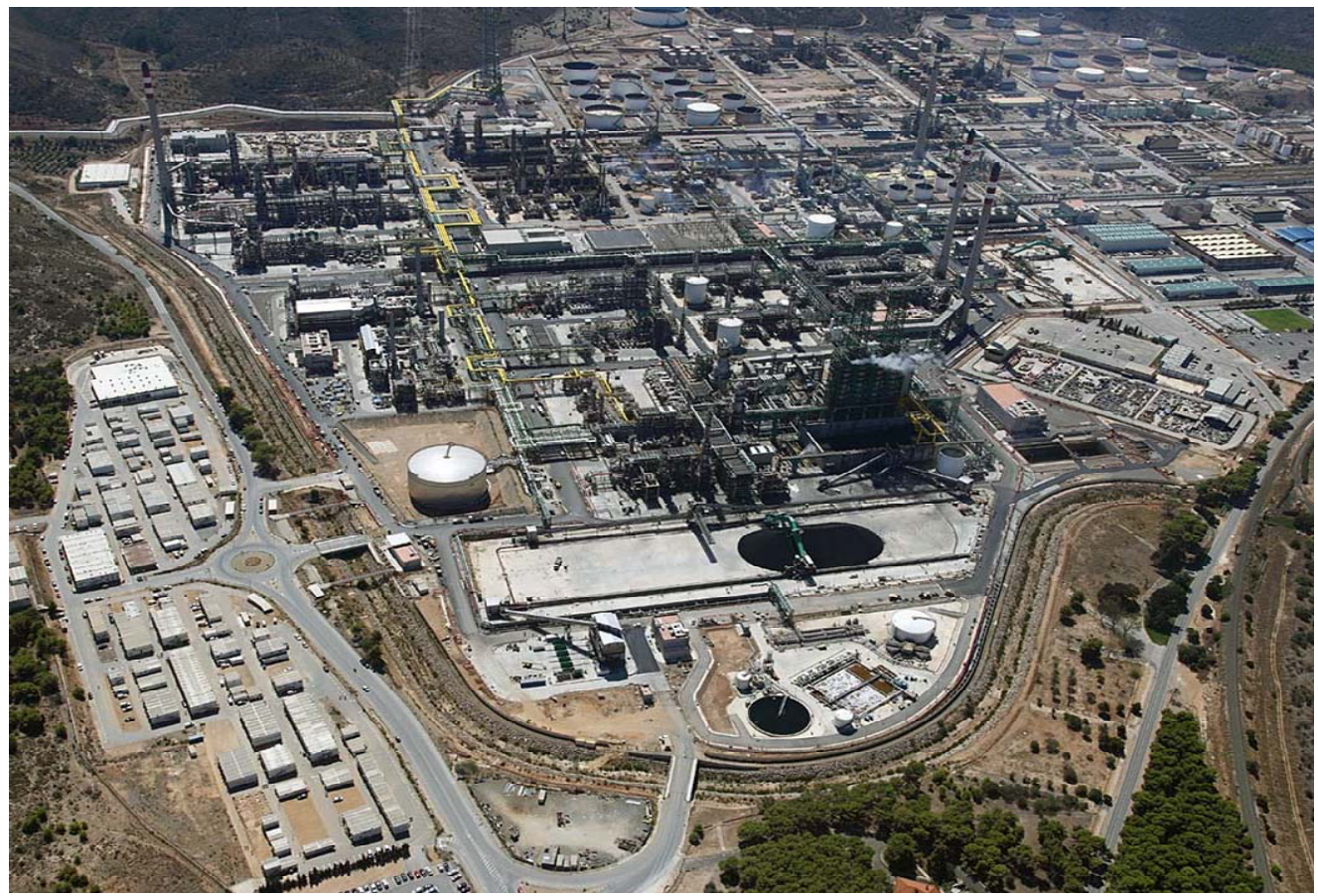

Fuente: Repsol. 
El Poblado de Repesa (Figura 6), desaparecido y cuyo espacio ocupa la ampliación de la refinería, contó con 447 viviendas construidas en varias fases. La primera, de 223 viviendas, se inauguró en 1950, el año de la puesta en funcionamiento de la refinería. Posteriormente se construyeron en dos etapas 108 y 163 casas, también de una y dos plantas, las últimas en 1963 (Jiménez, 2011). Eran los hogares de los empleados de la refinería y sus familias. El Poblado contaba con centros educativos de enseñanza (infantil, primaria y secundaria), clínica, iglesia, comercios de alimentación, amplias instalaciones deportivas, centro cultural recreativo y salón de actos. También disponía de muy buena conexión con la ciudad de Cartagena a través de autobuses. De los 1.001 habitantes censados en el año 1991 en el Valle de Escombreras pasan a 157 en el año 2000 y 13 en 2015, todos ellos residentes en la Central Térmica.

Figura 6. Poblado de Repesa en la proximidad de la refinería antes de su demolición.

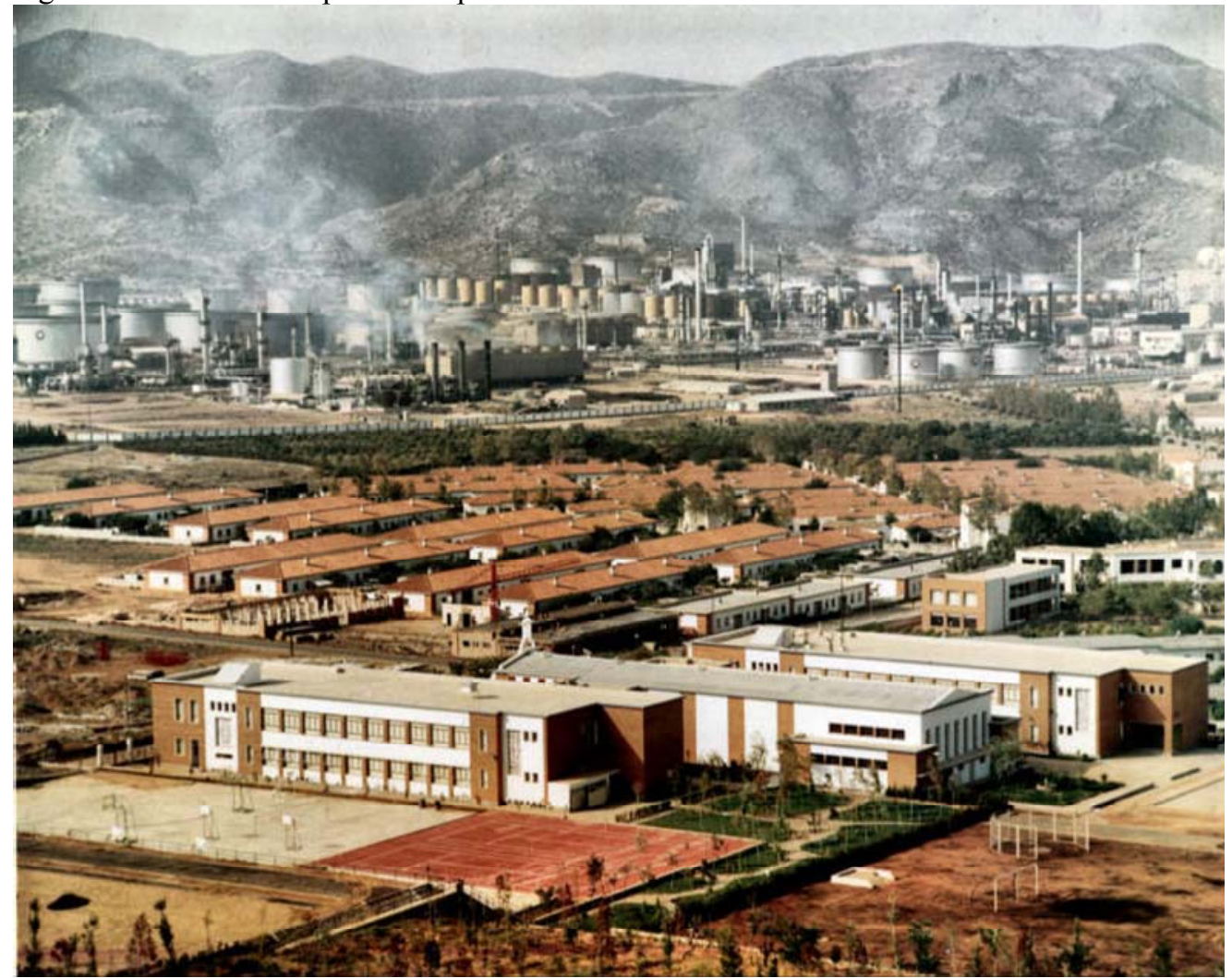

Fuente: http://lapaginadelpoblado.webcindario.com/ 


\section{Incidencia de la refinería sobre la actividad del Puerto de Cartagena}

La Dársena de Escombreras, en el Puerto de Cartagena, dispone de una terminal de atraque de petroleros de hasta 250.000 T.P.M. (Toneladas de peso muerto), compuesta esencialmente por el atraque y plataforma para la descarga de crudo (Figura 7). El atraque se compone de cuatro duques de Alba (estructuras aisladas que sirven para dar apoyo lateral y amarre a los buques), siendo en la plataforma donde se instalan cinco brazos articulados tipo pantógrafo, cada uno de $400 \mathrm{~mm}$. de diámetro que permite un ritmo de descarga de 3.300 Tm de crudo a la hora. Entre los muelles de esta Dársena y la refinería existen grandes tuberías: una de $60 "$ con capacidad de $10.500 \mathrm{Tm} / \mathrm{h}$ y otra de 24" con $1.800 \mathrm{Tm} / \mathrm{h}$, para el bombeo de crudos hasta los tanques de almacenamiento; cuatro para la carga de fuelóleo de 10", 12", 16" y 16" con capacidad de 500 a $700 \mathrm{Tm} / \mathrm{h}$ cada una; dos de gasóleo de 12 " y $500 \mathrm{Tm} / \mathrm{h}$ cada una; dos de gasolina de 10" y 12" y capacidad de $400 \mathrm{Tm} / \mathrm{h}$ cada una; y dos de aceite de 6" y 120 $\mathrm{Tm} / \mathrm{h}$ cada una. Para la carga y descarga de gases licuados (butano y propano) existe una tubería de 6" con capacidad de $80 \mathrm{Tm} / \mathrm{h}$ y una tubería de 3" para retorno de gases (Autoridad Portuaria de Cartagena, 2006).

Figura 7. Dársena de Escombreras en el Puerto de Cartagena.

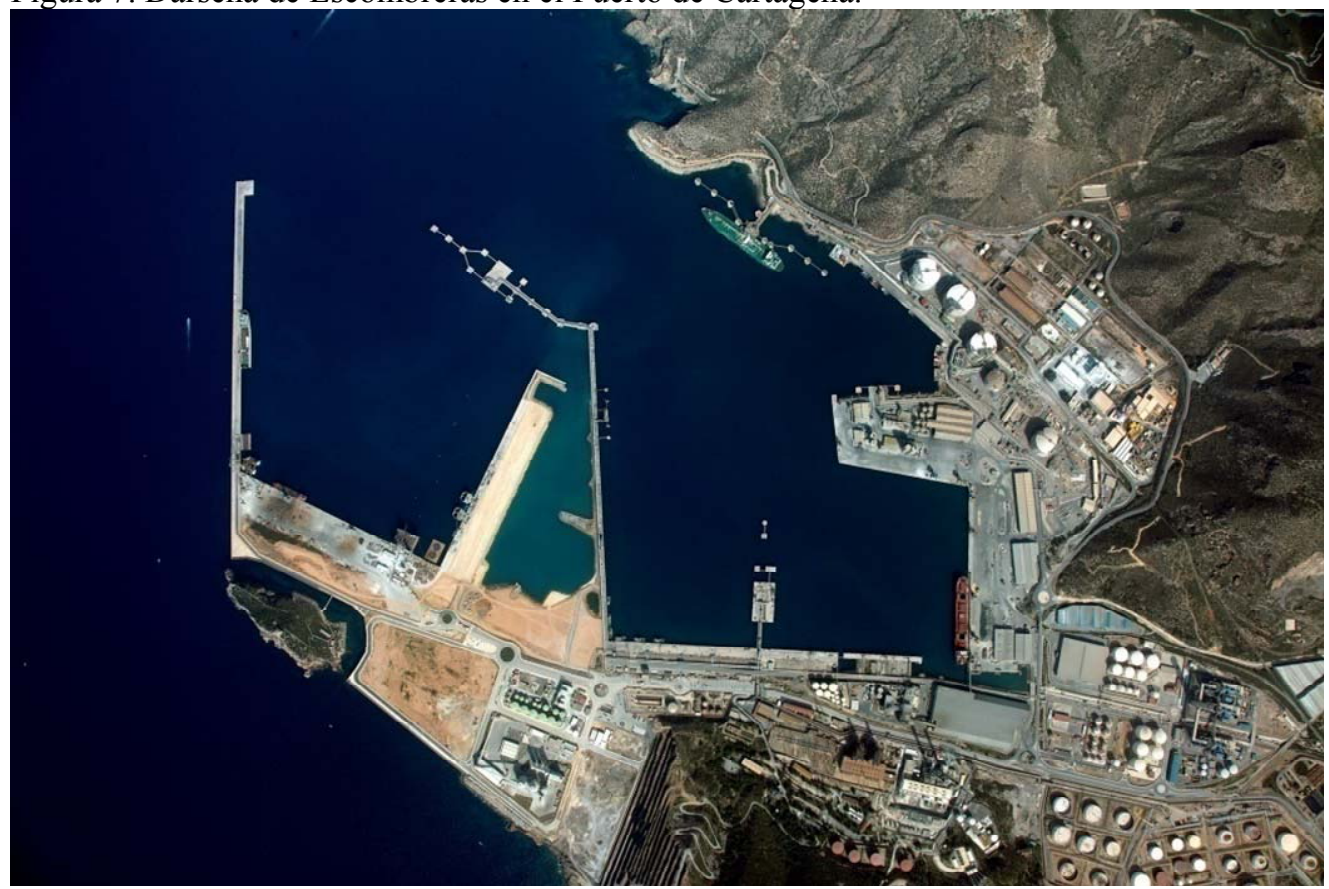

Fuente: Autoridad Portuaria de Cartagena. 
Desde finales de los años cincuenta la Autoridad Portuaria ha cedido a la refinería la ocupación del suelo de la citada dársena durante periodos de tiempo renovables, con el fin de poder desarrollar las actividades necesarias (Cuadro 6). La cifra de ingresos por tales concesiones asciende en 2015 a casi cuatro millones de euros.

Cuadro 6. Obras y actividades autorizadas a Repsol por la Autoridad Portuaria del Puerto de Cartagena en la dársena de Escombreras. 1959-2008.

\begin{tabular}{|c|c|c|c|}
\hline Designación & $\begin{array}{c}\text { Fecha de } \\
\text { otorgamiento }\end{array}$ & $\begin{array}{c}\text { Año de } \\
\text { caducidad }\end{array}$ & $\begin{array}{c}\text { Importe anual } \\
\text { euros }\end{array}$ \\
\hline $\begin{array}{l}\text { Ocupación de terrenos para } \\
\text { construcción de talleres y almacenes }\end{array}$ & 5-06-1959 & $16-12-2027$ & $19.452,84$ \\
\hline $\begin{array}{l}\text { Separador de residuos petrolíferos } \\
\text { para el deslastre de petroleros }\end{array}$ & $20-03-1963$ & $16-12-2027$ & $16.433,89$ \\
\hline $\begin{array}{l}\text { Ocupación y cerramiento de parcela. } \\
\text { Terminal petrolífera de Escombreras }\end{array}$ & $22-01-1967$ & $16-12-2027$ & $9.650,08$ \\
\hline $\begin{array}{c}\text { Tendido aéreo de tuberías en Muelle } \\
\text { Maese y Bastarreche }\end{array}$ & $21-12-1994$ & $16-12-2027$ & $11.282,23$ \\
\hline $\begin{array}{c}\text { Red de agua de mar. Servicio de } \\
\text { contraincendios }\end{array}$ & $26-05-1966$ & $16-12-2022$ & $1.640,86$ \\
\hline $\begin{array}{c}\text { Modificación de la concesión } \\
\text { otorgada el 8-3-2000, y otorgamiento } \\
\text { de concesión para la instalación de } \\
\text { una nueva terminal de } 250.000 \mathrm{Tm}\end{array}$ & $16-10-2000$ & $10-03-2030$ & $3.199 .033,57$ \\
\hline $\begin{array}{c}\text { Uso y explotación de instalaciones } \\
\text { con destino a la carga y descarga de } \\
\text { productos petrolíferos en los frentes } \\
\text { E-013, E-014 y E-015 }\end{array}$ & $30-03-2004$ & $27-02-2021$ & $539.338,31$ \\
\hline $\begin{array}{c}\text { Uso y explotación de instalaciones } \\
\text { para trasiego de Gas Licuado del } \\
\text { Petróleo en los frentes de atraque E- } \\
013 \text { y E-014 }\end{array}$ & $30-03-2004$ & $27-02-2021$ & $74.994,62$ \\
\hline $\begin{array}{l}\text { Instalación de un centro de } \\
\text { transformación interior abonado de } \\
1.000 \text { kva para la alimentación de las } \\
\text { instalaciones terminales marítimas }\end{array}$ & $23-11-2006$ & $10-03-2030$ & $1.331,98$ \\
\hline $\begin{array}{l}\text { Edificio de control central en el } \\
\text { Muelle Maese }\end{array}$ & $23-11-2006$ & $10-03-2030$ & $3.279,21$ \\
\hline $\begin{array}{l}\text { Separador vertical de capacidad de } \\
\text { tratamiento de } 2.500 \mathrm{~m}^{3} \text { de residuos } \\
\text { petrolíferos procedentes de deslastres, } \\
\text { ampliación de la instalación } \\
\text { deparador de residuos petrolíferos }\end{array}$ & $12-12-2007$ & $10-03-2030$ & $31.497,15$ \\
\hline Construcción de emisario submarino & 24-09-2008 & $10-03-2030$ & 124,56 \\
\hline Total & & & $3.908 .059,30$ \\
\hline
\end{tabular}

Fuente: Autoridad Portuaria de Cartagena. 
Para Repsol, uno de los principales valores de su refinería es la Dársena de Escombreras, uno de los puertos más seguros del Mediterráneo, que permite la operación óptima de buques prácticamente todos los días del año. En los 8 frentes de atraque que Repsol tiene en la misma atracan petroleros que transportan una amplia variedad de tipos de crudo, que llegan hasta estas instalaciones desde todas partes del mundo (Repsol, 2012b). La ampliación de su capacidad de producción se refleja en el incremento de la actividad del puerto, ya que a partir de 2009 sube todo los años el número de embarcaciones que faenan en el mismo aumenta año tras año de forma paralela al aumento del petróleo destilado en la refinería de Cartagena. Como se presenta en el cuadro 7 los buques mercantes predominan y se indican los cruceros para ver su reciente incidencia en el puerto de Cartagena en relación con el total de embarcaciones.

Cuadro 7. Incidencia de los buques mercantes en el total de embarcaciones llegadas al Puerto de Cartagena. 2006-2015.

\begin{tabular}{|c|r|r|r|r|}
\hline Año & \multicolumn{1}{|c|}{$\begin{array}{c}\text { Total } \\
\text { embarcaciones }\end{array}$} & \multicolumn{1}{c|}{$\begin{array}{c}\text { Buques } \\
\text { mercantes }\end{array}$} & \multicolumn{1}{c|}{$\begin{array}{c}\text { Cruceros } \\
\text { turísticos }\end{array}$} & $\begin{array}{c}\text { \% buques } \\
\text { mercantes/total } \\
\text { embarcaciones }\end{array}$ \\
\hline 2006 & 1.736 & 1.661 & 34 & 95,7 \\
\hline 2007 & 1.556 & 1.502 & 48 & 96,5 \\
\hline 2007 & 1.397 & 1.330 & 41 & 95,2 \\
\hline 2009 & 1.483 & 1.387 & 49 & 93,5 \\
\hline 2010 & 1.556 & 1.423 & 77 & 91,3 \\
\hline 2011 & 1.570 & 1.434 & 79 & 97,6 \\
\hline 2012 & 1.767 & 1.725 & 115 & 96,4 \\
\hline 2013 & 1.832 & 1.766 & 109 & 96,0 \\
\hline 2014 & 1.872 & 1.798 & 109 & 95,3 \\
\hline 2015 & 1.954 & 1.862 & & \\
\hline
\end{tabular}

Fuente: Autoridad Portuaria de Cartagena.

Cuatro quintas partes de las mercancías que trasiegan desde el Puerto de Cartagena son graneles líquidos (Cuadro 8). Se trata de petróleo crudo, que abastece las refinerías de Puertollano y Escombreras, y derivados del petróleo. El volumen de gas natural licuado también es significativo, teniendo en cuenta la capacidad de la planta de regasificación de Enagás, pero en el conjunto total de mercancías supone solo el $4,3 \%$ (Cuadro 9). 
Cuadro 8. Incidencia de los graneles líquidos en el tráfico de mercancías del Puerto de Cartagena. 2007-2015. Tm.

\begin{tabular}{|c|c|c|c|}
\hline Año & Total tráfico portuario & Graneles líquidos & \% Graneles líquidos/tráfico total \\
\hline 2007 & 23.939 .469 & 17.532 .087 & 73,24 \\
\hline 2008 & 25.640 .910 & 20.109 .630 & 78,43 \\
\hline 2009 & 20.513 .425 & 16.168 .779 & 78,82 \\
\hline 2010 & 19.104 .921 & 15.131 .726 & 79,20 \\
\hline 2011 & 22.652 .648 & 17.862 .896 & 78,86 \\
\hline 2012 & 30.098 .801 & 24.229 .644 & 80,50 \\
\hline 2013 & 29.374 .439 & 23.719 .898 & 80,75 \\
\hline 2014 & 32.331 .273 & 25.804 .768 & 79,81 \\
\hline 2015 & 32.458 .113 & 25.621 .089 & 78,94 \\
\hline
\end{tabular}

Fuente: Autoridad Portuaria de Cartagena.

Cuadro 9. Graneles líquidos (Tm) movilizados en el Puerto de Cartagena (2015).

\begin{tabular}{|c|c|c|c|c|}
\hline Mercancías & Embarcadas & Desembarcadas & Total & \% \\
\hline Petróleo crudo & 0 & 16.077 .179 & 16.077 .179 & 62,75 \\
\hline Fueloil & 338.107 & 1.038 .961 & 1.377 .068 & 5,37 \\
\hline Gasoil & 2.285 .165 & 172.060 & 2.457 .225 & 9,59 \\
\hline Gasolina & 813.517 & 108.842 & 922.359 & 3,60 \\
\hline Asfalto & 55.340 & 0 & 55.340 & 0,22 \\
\hline $\begin{array}{c}\text { Otros productos } \\
\text { petrolíferos }\end{array}$ & 2.501 .944 & 15.458 & 2.517 .402 & 9,83 \\
\hline $\begin{array}{c}\text { Gases energ. del } \\
\text { petróleo }\end{array}$ & 63.140 & 76.117 & 139.257 & 0,54 \\
\hline Productos químicos & 12.606 & 448.522 & 461.128 & 1,80 \\
\hline Aceites yradas & 120.254 & 222.138 & 342.392 & 1,34 \\
\hline Gas natural & 108.793 & 985.174 & 1.093 .967 & 4,27 \\
\hline Biocombustibles & 173.023 & 4.749 & 177.772 & 0,69 \\
\hline Total & 6.471 .889 & 19.149 .200 & 25.621 .089 & 100,00 \\
\hline
\end{tabular}

Fuente: Autoridad Portuaria.

\section{Capacidad de refino en España}

El parque de instalaciones que operan en España en la actualidad sigue siendo de 10 refinerías (Cuadro 10) con una capacidad de proceso de destilación de petróleo de 77,8 millones de Tm, frente a las 62 del año 1986 (cuadro 2), por tanto en tres décadas se ha ampliado en un $25,3 \%$.

Las refinerías españolas se encuentran situadas estratégicamente a lo largo de la costa, próximas a los principales centros de consumo, excepto la refinería de Puertollano, que es la única situada en el interior, pero muy próxima a uno de los principales centros de consumo como es Madrid y todo su entorno. Este reparto 
supone una gran ventaja desde el punto de vista de la seguridad del suministro, al no estar concentradas varias refinerías en una sola localidad, como es muy frecuente en otros países de la Unión Europea (Mazarrasa, 2013).

Cuadro 10. Capacidad de refino de petróleo en España (2015) ${ }^{3}$.

\begin{tabular}{|c|c|c|c|c|c|c|}
\hline Refinería & $\begin{array}{c}\text { Destilación } \\
\text { atmosférica } \\
\text { Mt/año }\end{array}$ & $\begin{array}{c}\text { Destilación } \\
\text { atmosférica } \\
\text { Bbl/día }\end{array}$ & $\begin{array}{c}\text { FCC } \\
\text { Equivalente } \\
\text { Mt/año }\end{array}$ & $\begin{array}{c}\text { Us. } \\
\text { Proceso }\end{array}$ & $\begin{array}{c}\text { Capacidad } \\
\text { Mt/año }\end{array}$ & $\begin{array}{c}\text { Capacidad } \\
\text { kbbl/día }\end{array}$ \\
\hline Cartagena & 11,0 & 220.000 & 8,4 & Dest. Atm. & 77,80 & 1.556 \\
\hline Coruña & 6,0 & 120.000 & 4,0 & Dest. Vacío & 30,40 & 546 \\
\hline Puertollano & 7,5 & 150.000 & 4,9 & Dest. Vacío & 2,74 & 50 \\
\hline Tarragona & 9,0 & 180.000 & 3,9 & FCC & 10,36 & 198 \\
\hline Bilbao & 11,0 & 220.000 & 7,0 & Hydrocrakin & 9,65 & 186 \\
\hline Tenerife & 4,5 & 90.000 & 0,7 & Visbreaking & 8,84 & 153 \\
\hline Algeciras & 12,0 & 240.000 & 2,8 & Coquización & 8,80 & 153 \\
\hline Huelva & 10,0 & 200.000 & 4,6 & Reformado & 9,14 & 211 \\
\hline Castellón & 5,4 & 110.000 & 3,4 & HDS/HDT & 49,87 & 1.052 \\
\hline Asesa & 1,4 & 28.000 & & & & \\
\hline Total & 77,8 & 1.558 .000 & 39,6 & & & \\
\hline
\end{tabular}

Fuente: Asociación Española de Operadores de Productos Petrolíferos.

El refino español compite con el europeo en condiciones de mercado enteramente liberalizado y sus instalaciones, en cuanto a capacidad de conversión y desulfuración, están a la cabeza de las de la Unión Europea como se detalla en el cuadro 5. A pesar del desfavorable entorno, el refino español mantuvo su plan inversor, superando los 6.500 millones de euros en el periodo 2008-2013. Un ambicioso programa de inversiones para adaptar el refino español a la demanda, conseguir mejoras medioambientales y alcanzar una mayor eficiencia energética. En 2009 se pusieron en

${ }^{3}$ Destilación atmosférica: tratamiento primario del crudo.

$B B l$ : Barril de 159 litros.

FCC: Cracking catalítico para la producción de gasolinas y, en menor medida, de petróleo.

Cracking: rotura de las moléculas en condiciones controladas para obtener productos específicos (gasolinas y gasóleos, más otros).

Destilación a vacío: tratamiento físico del residuo de la destilación atmosférica. Prepara la carga a las unidades de craking.

Hidrocraking: craking en una atmósfera de hidrógeno. Se usa para producir gasóleos de alta calidad, exentos de azufre.

Visbreaking: craking térmico suave para obtener gasóleos pesados y fueles de baja viscosidad. Coquización: craking térmico severo para obtener destilados de baja calidad (alto azufre) y coque de petróleo.

Reformado: transformación en naftas de Gases Licuados del Petróleo y gasolinas de alto octano.

HDS/HDT: Tratamiento con hidrógeno para eliminar el azufre. 
marcha los proyectos de Castellón y Algeciras, en 2010 el de Huelva, y en 2011 entraron en funcionamiento las nuevas unidades de Cartagena y Murcia. Ya en 2014 se completará el "Proyecto Esfera" en la refinería de Castellón para aprovechar las instalaciones recientemente construidas en la dársena sur del puerto para transportar gas licuado del petróleo por barco (Asociación Española de Operadores de Productos Petrolíferos, 2016).

Figura 8. Mapa de infraestructuras de la Compañía Logística de Hidrocarburos.

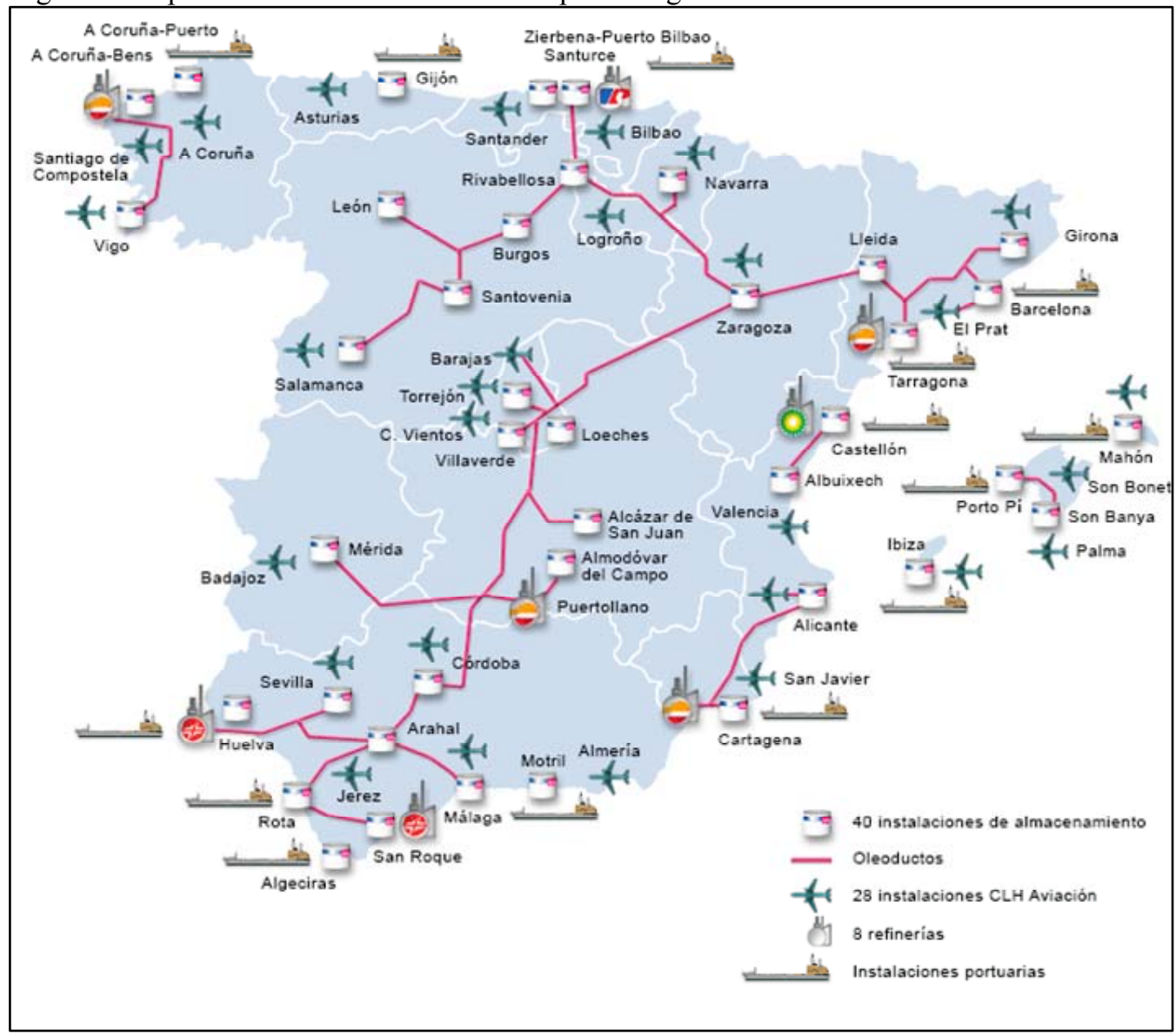

Fuente: Compañía Logística de Hidrocarburos.

Este esfuerzo está permitiendo la adaptación de las refinerías a la mayor demanda de destilados medios produciendo más de 8 millones de Tm./año adicionales. Además permite a las refinerías españolas reducir el impacto medioambiental y mejorar su eficiencia energética. Se trata de una apuesta estratégica para preservar la 
competitividad en un sector cada vez más global. Todo ello ha tenido reflejo en una mejora de la seguridad de suministro y la balanza comercial española gracias fundamentalmente a la disminución de las importaciones de destilados medios. De hecho, el saldo neto exportador de productos petrolíferos se ha elevado en 2015 hasta 5,9 millones de Tm. Además, estas inversiones han generado un importante volumen de empleo, tanto directo como indirecto, de larga duración y cualificado, y han fomentado la creación de una red de empresas de servicio industrial de primer nivel. En las refinerías españolas ya existentes se aprobaron las siguientes inversiones para el aumento en la capacidad de procesamiento de crudo (unidades de destilación atmosférica y a vacío en Huelva, Cartagena, Algeciras) y la transformación de fuelóleos y gasóleos pesados en diésel (cokers en Castellón, Cartagena y Bilbao, hydrocrackers en Huelva, Cartagena y Algeciras). En 2015, las cantidades de crudo y materia prima procesadas fueron 65,66 millones de toneladas, un 6,9\% más que en el año anterior (Asociación Española de Operadores de Productos Petrolíferos, 2016).

Una de las ventajas con las que cuentan las refinerías españolas es que disponen de un sistema logístico muy eficiente para la distribución de sus productos, y su localización es muy adecuada para la exportación de productos excedentes (Espejo, 2008b). La red de la Compañía Logística de Hidrocarburos cuenta con $4.000 \mathrm{~km}$ (Figura 8) y varios operadores manejan de forma integrada sus refinerías, lo que les aporta grandes ventajas operativas y sinergias en las fabricaciones de productos intermedios y productos acabados. Como ejemplo de esta flexibilidad, mencionamos el oleoducto reversible que une las refinerías de Puertollano y Cartagena, propiedad de Repsol, o la conexión marítima La Rábida-San Roque para los intercambios entre las refinerías de Cepsa (Mazarrasa, 2013).

\section{Incidencia de la ampliación de la refinería de Cartagena en el sector del petró- leo en España}

La ampliación de la refinería de Cartagena ha tenido un gran impacto en el sector del petróleo en España, por el incremento en las importaciones de crudo, en la producción total de las refinerías y en las exportaciones de productos petrolíferos. Las exportaciones han sido fundamentales porque han permitido seguir funcionando a estas industrias en años de crisis con una caída reseñable en el consumo de productos petrolíferos (cuadro 11). La nueva refinería también ha contribuido a ampliar y modificar su aportación a la producción nacional de destilados del petróleo (Cuadro 12). 
Cuadro 11. Importaciones de crudo, producción de las refinerías, consumo interior y exportaciones de productos petrolíferos en España. 2004-2014. Miles de Tm.

\begin{tabular}{|c|r|r|r|r|}
\hline Año & $\begin{array}{c}\text { Importaciones } \\
\text { de crudo }\end{array}$ & $\begin{array}{c}\text { Producción de } \\
\text { las refinerías }\end{array}$ & $\begin{array}{c}\text { Consumo } \\
\text { interior de } \\
\text { productos } \\
\text { petrolíferos }\end{array}$ & $\begin{array}{c}\text { Exportaciones } \\
\text { de productos } \\
\text { petrolíferos }\end{array}$ \\
\hline 2004 & 59.409 & 59.482 & 73.510 & 7.969 \\
\hline 2005 & 59.834 & 60.310 & 74.809 & 8.258 \\
\hline 2006 & 60.475 & 61.350 & 73.969 & 9.840 \\
\hline 2007 & 57.509 & 59.855 & 75.003 & 10.714 \\
\hline 2008 & 58.508 & 60.544 & 72.535 & 11.089 \\
\hline 2009 & 52.297 & 57.236 & 68.445 & 11.579 \\
\hline 2010 & 52.461 & 57.644 & 67.096 & 13.054 \\
\hline 2011 & 52.147 & 58.649 & 64.293 & 17.125 \\
\hline 2012 & 58.697 & 61.346 & 59.984 & 18.547 \\
\hline 2013 & 57.871 & 60.502 & 54.642 & 19.337 \\
\hline 2014 & 59.054 & 60.563 & 53.870 & 21.818 \\
\hline 2015 & 64.628 & 64.985 & 55.294 & \\
\hline
\end{tabular}

Fuente: Corporación de Reservas Estratégicas de Productos Petrolíferos.

Cuadro 12. Aportación de algunos derivados del petróleo de la refinería de Cartagena al conjunto de la producción de España. 2010 y 2015.

\begin{tabular}{|c|c|c|c|c|c|c|c|}
\hline & \multicolumn{3}{|c|}{2010} & \multicolumn{3}{|c|}{2015} & \multirow{2}{*}{$\begin{array}{c}\text { Incremento de la } \\
\text { aportación de } \\
\text { Cartagena }\end{array}$} \\
\hline & $\begin{array}{c}\text { Cartagena } \\
\text { Tm }\end{array}$ & España Tm & $\begin{array}{c}\% \text { de } \\
\text { España }\end{array}$ & $\begin{array}{c}\text { Cartagena } \\
\text { Tm }\end{array}$ & $\begin{array}{c}\text { España } \\
\text { Tm }\end{array}$ & $\begin{array}{c}\% \text { de } \\
\text { España }\end{array}$ & \\
\hline Gasóleos & 1.398 & 22.900 & 6,10 & 5.845 & 27.485 & 21,27 & 248,35 \\
\hline Gasolinas & 380 & 8.013 & 4,74 & 502 & 9.105 & 5,51 & 16,26 \\
\hline Querosenos & 201 & 6.335 & 3,17 & 1.149 & 9.511 & 12,08 & 280,75 \\
\hline Fuelóleos & 457 & 8.344 & 5,48 & 84 & 3.984 & 2,11 & $-61,50$ \\
\hline G.L.P. & 44 & 1.456 & 3,02 & 222 & 1.699 & 13,07 & 332,38 \\
\hline
\end{tabular}

Fuente: Repsol y Corporación de Reservas Estratégicas de Productos Petrolíferos

\section{El papel de la refinería en la instalación de otras industrias energéticas del Valle de Escombreras}

Durante décadas la producción eléctrica en España ha tenido uno de sus pilares en las centrales térmicas de fuelóleo. La de Escombreras fue pionera y durante décadas permitió al Sureste Peninsular contar con la electricidad necesaria para su desarrollo. Medio siglo después la implantación en nuestro país de los biocarburantes llevó a la construcción en el mismo territorio de la primera planta de bioetanol. Por ello hacemos una breve reseña sobre estas industrias vinculadas directamente a la refinería. 


\subsection{La Central Térmica}

La Central Térmica de Escombreras entra en los planes de Hidroeléctrica Española a comienzos de la década de 1950. En 1955 se inician las obras de instalación de los primeros grupos, obras que tras sucesivas ampliaciones llegan hasta 1968 con cinco grupos que suman una potencia de $858 \mathrm{MW}$. Es la primera central térmica que funciona con fuelóleo, del que se abastece de su vecina refinería. Comienza su producción en $1957 \mathrm{y}$, tras medio siglo de actividad, genera electricidad hasta 2007, año en el que se desmantela para la construcción por parte de Iberdrola de una nueva central de ciclo combinado de dos grupos de $400 \mathrm{MW}$. Esta central se abastece de gas natural procedente de la cercana planta de regasificación de gas natural que Enagás tiene en el Valle de Escombreras. La Central Térmica de Escombreras, junto con el agua de la Mancomunidad de los Canales del Taibilla, que hizo también posible su instalación, son dos pilares del desarrollo económico de Murcia y del Sureste Peninsular durante la segunda mitad del siglo XX. De la magnitud de su producción eléctrica en algunos momentos dan cuenta estos datos: su aportación a la generación eléctrica nacional asciende al 7,8 \% en 1967 y al $9 \%$ en 1968 (Espejo, 2008).

\subsection{Las plantas de biocarburantes}

En 1996 se constituye Ecocarburantes Españoles, participada por Abengoa en un 95\% y por el Instituto para la Diversificación y Ahorro de la Energía en un 5\%. Esta sociedad instala en las proximidades de la refinería una planta de bioetanol con una capacidad de $118.000 \mathrm{Tm} / \mathrm{año}$. Con una inversión de 71 millones de euros, es la primera planta de biocarburantes que se construye en España y comienza a producir en el año 2000 (Instituto para la Diversificación y Ahorro de la Energía, 2002).

En 2008 se inaugura, también en el Valle de Escombreras, la planta de biodiésel propiedad de la multinacional italiana Saras Energía. Con una inversión de 43 millones de euros se construye una instalación con una capacidad de producción de 200.000 Tm/año, ¥que está conectada con la refinería (Espejo, Millán y García, 2016)

\section{Conclusiones}

Las infraestructuras energéticas son instalaciones básicas para el desarrollo de todas las sociedades. En este caso, la refinería de Cartagena se implanta en una ciudad que une a su localización estratégica en el Mediterráneo ser una base naval de referencia.

Dos factores fueron fundamentales para su construcción: el empeño del Gobierno del General Franco y la colaboración de empresas norteamericanas del sector del petróleo. Repsol es la denominación que reciben los lubricantes producidos en esta refinería, y esta marca acaba dando nombre a la multinacional petrolera española. 
Durante 65 años ha vivido etapas de crecimiento y de incertidumbre, por las crisis del petróleo en los años setenta, por la competencia que le han hecho las nuevas refinerías, y por la caída en el consumo de productos petrolíferos de los últimos años.

La crisis que ha vivido nuestro país desde finales de la primera década de este siglo no han sido un obstáculo para que Repsol invirtiera más de 3.000 millones de euros para su ampliación y modernización. A ello han contribuido: las características del puerto de Cartagena, que en su dársena de Escombreras cuenta con las infraestructuras necesarias para el desarrollo de su gran actividad; su conexión mediante un oleoducto doble con la refinería interior de Puertollano, propiedad de Repsol en ambos casos, que recibe el crudo desde Cartagena, y permite a aquella tener una salida de sus productos a un puerto, $\mathrm{y}$ a la de Cartagena la conexión interior a la red nacional de oleoductos que opera la Compañía Logística de Hidrocarburos; la disponibilidad de suelo próximo y necesario para las nuevas instalaciones, en el espacio que ocupó el Poblado de Escombreras, que fue lugar de residencia de una parte de la plantilla de la refinería durante décadas; y por último y no menos importante, la necesidad de obtener gasóleos y querosenos, productos de los que España era deficitaria.

Junto a la refinería, Hidroeléctrica Española instaló la primera central térmica de fuelóleo de la España Peninsular, y durante medio siglo su producción eléctrica ha sido fundamental para el desarrollo económico de esta zona de España. Más recientemente, la implantación de los biocarburantes ha llevado a que se construyan en sus proximidades dos plantas: una de bioetanol, que fue la primera que se instaló en España, y otra de biodiésel.

\section{Referencias bibliográfícas}

Asociación Española de Operadores de Productos Petrolíferos (2016): Memoria AOP 2015. Madrid.

Autoridad Portuaria de Cartagena (2016): Puerto de Cartagena. Memoria Anual 2015. Cartagena.

Bailly, A. y Beguin, H. (1992): Introducción a la Geografía Humana. Barcelona, Masson.

Ballestero, A. (1993): Juan Antonio Suanzes 1891-1987. La política industrial de la postguerra. Madrid, Lid Editorial Empresarial.

Brufau Niubó, A. (2012): Presentación. En Repsol Cartagena 1950-2012, Madrid, Repsol, 7-9

Centeno, R. (1976): España y el petróleo. Una defensa de la planificación del sector público. Madrid, Cuadernos para el Diálogo.

Comisión Nacional de Energía (2006): Cronología del sector Petrolero español. Madrid.

Compañía Logística de Hidrocarburos (2016): Informe Anual del Grupo CLH 2015.

Cortina, J. (1998): La evolución de la economía de Cartagena (1940-1996). Alicante, Caja de Ahorros del Mediterráneo.

Espejo Marín, C. (2008a): La distribución al por mayor de productos petrolíferos en España. Papeles de Geografía, 47-48, 55-80. 
Espejo Marín, C. (2008b): La electricidad térmica en la Región de Murcia. Medio siglo de contribución al desarrollo. En Estudios sobre desarrollo regional. Murcia, Universidad de Murcia, 95-129.

Espejo Marín, C., Millán Piñero, D. y García Marín, R. (2016): Contribución al sector de los biocarburantes en España. Scripta Nova, XX, 548.

Fernández Gonzálo, M. (2008): Repsol YPF: una nueva refinería en Cartagena. Cuadernos de Energía, 19, 72-81.

Flores Jiménez, F. (1966): Escombreras. Madrid, Publicaciones Españolas.

Jiménez G. (2011): Añoranzas del Poblado de Repesa. Diario La Vedad. Edición Cartagena, 30 de octubre de 2011. http://www.laverdad.es/murcia/v/20111030/cartagena/anoranzaspoblado-repesa-20111030.html

Martín Aceña, P. y Comín, F. (1990): La acción regional del Instituto Nacional de Industria, 1941-1976. En Nadal, J. y Carrerras, A. (Dirs. y Coords.): Pautas regionales de la industrialización española (siglos XIX y XX). Barcelona, Ariel, 379-419.

Haggett, P. (1979): Geography: a modern synthesis. New York, Harper \& Row.

Harvey, D. (1983): Teorías, leyes y modelos en Geografía. Madrid, Alianza Ediorial.

Martín Aceña, P. y Comín, F. (1991): INI. 50 años de industrialización en España. Madrid, Espasa-Calpe.

Mazarrasa Alvear, A. (2013): El refino en España y Portugal. Retos y oportunidades. Cuadernos de Energía, 39, 93-100.

Mérenne-Schoumaker, B. (2011): Géographie de l'énergie. Acteurs, lieux et enjeux. Paris, Éditions Belin.

Molina Ibáñez, M. (1991): Fuentes de energía y recursos minerales. En Bosque, J. y Vilà, J. (Dirs.): Geografía de España. Geografía Humana II. Barcelona, Editorial Planeta, 9-72.

Molina Ibáñez, M. (2001): Las fuentes de energía. En Gil Olcina, A. y Gómez Mendoza, J. (Coord.): Geografía de España. Barcelona, Ariel, 455-476.

Molina Ibañez, M. y Chicharro Fernández, E. (1990): Fuentes de energía y materias primas. Geografía de España. Madrid, Síntesis, vol. 9.

Puyol Antolín, R. (1978): Las fuentes de energía en España: petróleo, energía nuclear y energías de sustitución. Paralelo 37º , 2, 81-116.

Repsol (2012a): Cartagena 1950-2012. Madrid.

Repsol (2012b): Un complejo industrial en el futuro de la energía. Madrid.

Santamaría, J. (1988): El petróleo en España del monopolio a la libertad. Madrid, EspasaCalpe.

Tortella, G., Ballestero, A. y Díaz Fernández, J.L. (2003): Del Monopolio al libre mercado. La historia de la industria petrolera española. Madrid, LID Editorial Empresarial. 